\title{
PELUANG DAN TANTANGAN BISNIS HOTEL SYARIAH PADA MASYARAKAT KOSMOPOLITAN
}

\author{
Firqah Annajiyah Mansyuroh \\ UIN Antasari, Banjarmasin \\ e-mail: firqahannajiyahmansyuroh@gmail.com
}

\begin{abstract}
The purpose of the writing is because of the opportunities and challenges of hotel syariah in a cosmopolitan society that can survive and even progress in the cosmopolitan society. The author uses descriptive research with a qualitative analysis approach. The results of this study show opportunities for sharia hotels namely; The number of Muslims in the world continues to increase, the Islamic concept is accepted by moral universality, and sharia quality services. The challenge is that people are still unfamiliar with sharia-based hotels and training on sharia concepts must be done by business people for staff working in sharia botels.
\end{abstract}

Abstrak: Tujuan tulisan karena adanya peluang dan tantangan hotel syariah dalam masyarakat kosmopolitan yang dapat bertahan dan bahkan semakin maju di dalam tatanan masyarakat kosmopolitan. Penulis menggunakan jenis penelitian deskriptif dengan pendekatan analisis kualitatif. Hasil dari penelitian ini terlihat peluang untuk hotel syariah yaitu; Jumlah umat Islam dunia terus meningkat, konsep syariah diterima oleh universalitas moral, dan layanan kualitas syariah. Tantangannya yaitu masih belum akrabnya orangorang dengan hotel yang berbasis syariah dan pelatihan-pelatihan tentang konsep syariah harus dilakukan oleh pelaku bisnis untuk para staf yang bekerja di hotel syariah.

\section{Keywords: Cosmopolitan Society, Sharia Hotel, Sharia Compliance}

\section{Pendahuluan}

Dewasa ini, kesadaran masyarakat global terhadap produk yang bersertifikat syariah sangat meningkat. Semangat industri syariah dalam dekade terakhir ini semakin marak di berbagai belahan dunia, bahkan di negara yang penduduknya minoritas Muslim sekalipun. Inggris, Jepang, Korea, Thailand, dan negara-negara lainnya beradu dalam pengembangan perindustrian syariah di negaranya masing-masing. Masyarakat dunia kini tidak hanya memandang syariah sebagai suatu konsep yang dapat dipakai atau dimiliki oleh bangsa atau negara tertentu yang mayoritas penduduknya Muslim saja. Namun konsep ini sudah dipakai di belahan bumi yang minoritas Muslim sekali pun. Masyarakat dunia kini telah menjadi masyarakat kosmopolitan.

Masyarakat yang ikut dalam kosmopolitanisme pada dasarnya memberi ruang penting pada peran individu dalam membentuk komunitas. Dengan dampak globalisasi pada relasi-relasi sosial, kosmopolitanisme menegaskan bahwa perbedaan kultur individu, kelompok dan bangsa, dan dialog antar kelompok tersebut, sebagai batu pijakan dalam membangun tatanan komunitas global.

\footnotetext{
1 HM. Syamsudini, "Cinta Dan Toleransi Perspektif Fethullah Gulen," Edu Islamika 5, no. 2 (September 2, 2013): 378-97, http://ejournal.iainjember.ac.id/index.php/eduIslamika/article/view/42/ 35.
}

Secara umum kosmopolitanisme merupakan harapan ideal tentang warga dunia tanpa perbatasan, dan kosmopolitanisme bersumber dari inspirasi pemikiran humanitas rasional, sebuah nilai yang terkandung dalam diri setiap manusia. Sehingga konsep syariah sebagai salah satu nilai yang paling dasar bagi masyarakat Muslim dapat diterima dan diaplikasikan di mana pun. ${ }^{1}$

Di Indonesia sendiri sebagai negara yang memiliki penduduk penganut agama Islam terbesar di dunia, awalnya hanya menerapkan konsep syariah pada dimensi dasar seperti kebutuhan produk konsumsi dan penggunaan harian, yang kemudian disusul dengan lahirnya industri jasa keuangan syariah pada awal tahun $90-$ an. Saat ini persepsi mengenai industri syariah meningkat hingga ke ranah bisnis pariwisata atau yang sering disebut dengan halal tourism. Untuk memajukan industri wisata syariah, Kementerian Pariwisata Indonesia meluncurkan program Indonesia Muslim Travel Index (IMTI). Tahun 2018 ini Malaysia adalah negara yang menempati posisi pertama sebagai pariwisata syariah terbaik dunia, disusul oleh Indonesia dan Uni Emirat Arab yang samasama menempati peringkat dua. ${ }^{2}$

2 Muhammad Irzal Adiakurnia, "Kejar Wisata Halal Terbaik Dunia, Kemenpar Terapkan Index Wisata Muslim - Kompas.Com," Kompas, 2018, https://travel.kompas.com/read/2018/06/06/103647 727/ kejar-wisata-halal-terbaik-dunia-kemenparterapkan-index-wisata-Muslim. 
Pengelolaan bisnis hotel syariah kini telah menjadi tren pariwisata dunia serta pasar yang sangat menjanjikan. Ini karena wisata syariah bukan hanya meliputi keberadaan tempat wisata ziarah dan religi yang merupakan pengertian wisata 'keagamaan' pada zaman dahulu saja, melainkan pula mencakup wisata syariah dalam pengertian masyarakat modern, seperti restoran dan hotel yang menyediakan makanan halal dan tempat shalat, serta persyaratan lainnya sehingga mendapat label syariah. ${ }^{3}$ Peningkatan tren wisata syariah modern ini dapat dilihat pemenuhan 30 sampai 50 persen dari target 20.000.000 kunjungan wisatawan Indonesia pada 2019 nanti. Jika kita coba hitung nominal yang bisa didapatkan, rata-rata pengeluaran wisatawan dari Arab Saudi misalnya, adalah 1.750 sampai dengan 2.200 dolar Amerika per kunjungan, dengan lama tinggal rata-rata 12 hari. $^{4}$

Berdasarkan gambaran di atas, perkembangan industri wisata syariah dunia memberikan harapan besar yang menumbuhkan optimisme bagi pelaku bisnis hotel syariah, terlebih lagi dengan lahirnya Peraturan Menteri Pariwisata dan Ekonomi Kreatif Republik Indonesia Nomor 2 Tahun 2014 Tentang Pedoman Penyelenggaraan Usaha Hotel Syariah, dan praktiknya yang kini kian meluas. Tulisan ini akan mendeskripsikan tentang beberapa konsep bisnis hotel syariah yang menjadi tren ekonomi Islam global dari sisi perkembangan istilah dan praktiknya. Studi ini akan menelusuri pula bagaimana peluang praktik bisnis hotel syariah dari sisi potensi dan prospek pembangunan industri pariwisata syariah pada masyarakat kosmopolitan. Selain itu penulis juga akan mencoba menjabarkan tantangan-tantangan yang akan dihadapi oleh pelaku bisnis hotel syariah pada keadaan masyarakat kosmopolitan saat ini.

\section{Metode}

Penulis akan menggunakan pendekatan analisis kualitatif dan merupakan jenis penelitian deskriptif. Ada pun tujuan dari penelitian ini adalah untuk membuat deskripsi, gambaran, atau lukisan secara sistematis, faktual dan akurat mengenai fakta-fakta, sehingga mempermudah pemahaman dan penarikan kesimpulan.

Jenis data yang penulis pakai hanya data sekunder, data ini digunakan untuk mendukung

\footnotetext{
3 Aan Jaelani, "Halal Tourism Industry in Indonesia: Potential and Prospects," Munich Personal RePEc Archive, no. 3 January (2017): 1-22.

${ }^{4}$ Yanita Petriella, "Wisata Halal Beri Kontribusi 30\% Terhadap Target 20 Juta Kunjungan Wisman,” Bisnis Indonesia,

2018, http://industri.bisnis.com/read/20180830/12/833354
}

berbagai teori yang dibutuhkan. Ada pun jurnaljurnal dan tesis yang digunakan sebagai rujukan yaitu penelitian yang berkaitan tentang faktorfaktor yang mempengaruhi kinerja bisnis suatu hotel syariah, baik di Indonesia mau pun di luar negeri yang mana penelitian tersebut dilakukan kurang dari 10 (sepuluh) tahun terakhir agar lebih up-to-date dan relevan dengan masyarakat cosmopolitan.

Sebagai acuan dalam menentukan peluang dan tantangan bisnis hotel syariah, penulis memakai kriteria yang dipakai sebagai penilaian dalam Global Muslim Travel Index. Kriteria pembahasan dalam GMTI yaitu access, communication, environment, dan service. Selain itu penulis juga akan menggunakan nilai-nilai yang dipandang penting dalam dasar etika masyarakat kosmopolitan yaitu keramahan, kesiapan, dan keinginan untuk menyambut orang lain, sebagai pedoman pengambilan kesimpulan.

\section{Pembahasan}

\section{A. Konsep Bisnis Hotel Syariah}

Secara etimologis (lughawi) kata 'syariah' berasal dari kata berbahasa Arab al-syari'ah yang berarti 'jalan ke sumber air' atau jalan yang harus diikuti, yakni jalan ke arah sumber pokok bagi kehidupan (al-Fairuzabadiy, 1995: 659). Orangorang Arab menerapkan istilah ini khususnya pada jalan setapak menuju palung air yang tetap dan diberi tanda yang jelas terlihat mata (Ahmad Hasan, 1984: 7). Syariah diartikan jalan air karena siapa saja yang mengikuti syariah akan mengalir dan bersih jiwanya. ${ }^{5}$

Konsep bisnis hotel syariah berkembang menjadi sebuah pasar unik yang dengan cepat menjadi sangat menarik di seluruh Timur Tengah. Beberapa pengaruh utama yang diidentifikasi di balik keberhasilan konsep ini adalah semakin tersedianya dana dari mereka yang patuh kepada prinsip syariah dan peningkatan intra-regional di kawasan Timur Tengah \& Afrika Utara (Middle East \& North Africa atau MENA). Konsep ini sebenarnya tidak benar-benar baru, karena sebagian besar hotel yang dikembangkan di Arab Saudi adalah hotel yang memenuhi prinsip-prinsip syariah. Namun, pengenalan konsep di tempat lainnya selain daerah Timur Tengah telah menarik banyak perhatian dan minat. ${ }^{6}$

/wisata-halal-beri-kontribusi-30-terhadap-target-20juta-kunjungan-wisman.

5 https://www.suduthukum.com/2015/06/pengertianhukum-islam-syariah-fikih.html

${ }^{6}$ Paul Rosenberg and Hala Matar Choufany, "Spiritual Lodging-the Sharia-Compliant Hotel Concept" (Dubai, 2009), https://www.hvs.com/content/2856.pdf. 2. 
Di Indonesia misalnya, pemangku kepentingan industri pariwisata, baik pemerintah, Majelis Ulama Indonesia, swasta dan seluruh elemen masyarakat, bekerjasama untuk mengembangkan usaha pariwisata syariah sehingga kini telah lahir Peraturan Menteri Pariwisata dan Ekonomi Kreatif Republik Indonesia Nomor 2 Tahun 2014 Tentang Pedoman Penyelenggaraan Usaha Hotel Syariah, sebagai bentuk keseriusan dalam industri halal tourism. Begitu pula dengan negara tetangga, Malaysia, yang memberikan sertifikat oleh Jabatan Kemajuan Islam Malaysia (JAKIM) kepada hotel-hotel yang memiliki konsep syariah.

Pengertian bisnis hotel syariah jika menurut Peraturan Menteri Pariwisata dan Ekonomi Kreatif Republik Indonesia adalah penyediaan akomodasi berupa kamar-kamar di dalam suatu bangunan yang dapat dilengkapi dengan jasa pelayanan makan dan minum, kegiatan hiburan dan atau fasilitas lainnya secara harian dengan tujuan memperoleh keuntungan, yang penyelenggaraannya harus memenuhi prinsip-prinsip hukum Islam sebagaimana yang diatur fatwa dan/atau telah disetujui oleh Majelis Ulama Indonesia. Bisnis hotel syariah ini kemudian dibagi menjadi dua golongan yaitu hotel syariah hilal-1 dan hotel syariah hilal-2. Perbedaannya terletak pada nilai yang memenuhi seluruh kriteria yang diperlukan untuk melayani kebutuhan wisatawan. Kriteria yang memenuhi kebutuhan minimal wisatawan Muslim sebagai golongan hilal-1, sedangkan yang dapat melayani kebutuhan secara moderat digolongkan pada hilal$2 .^{7}$

Agar hotel sepenuhnya sesuai syariah, sangat penting untuk fasilitas-fasilitas seperti spa dan ruang olahraga, terpisah untuk pria dan wanita. Ini harus sudah diperhatikan sejak tahap pengembangan saat merancang denah hotel. Dari awal masuk lobby, hotel dengan label syariah sudah harus menyediakan bacaan yang Islami dan atau memiliki pesan moral berupa antara lain majalah

\footnotetext{
7 "Peraturan Menteri Pariwisata Dan Ekonomi Kreatif Republik Indonesia Nomor 2 Tahun 2014 Tentang Pedoman Penyelenggaraan Usaha Hotel Syariah," Pub. L. No. 2, Menteri Pariwisata dan Ekonomi Kreatif Indonesia (2014), https://peraturan.bkpm.go.id/jdih/userfiles/batang/P ermen_Parweka_2_2014.pdf.

8 "Lampiran Peraturan Menteri Pariwisata Dan Ekonomi Kreatif Republik Indonesia Nomor 2 Tahun 2014 Tentang Pedoman Penyelenggaraan Usaha Hotel Syariah Kriteria Mutlak Dan Kriteria Tidak Mutlak Usaha Hotel Syariah A. Kriteria Hotel Syariah Hilal 1," Pub. L. No. 2, Kementrian Pariwisata dan Ekonomi Kreatif Republik Indonesia

(2014),
}

Islam, tabloid Islam, buku ke Islaman, majalah dan buku motivasi, dan bukan majalah dengan gambar model fashion terkecuali fashion Muslim. Hiasan yang ada juga harus lah bernuansa Islami seperti kaligrafi. Lalu tempat tidur dan toilet tidak boleh ditempatkan di arah Mekah serta tidak diperkenankan pasangan yang bukan mahram untuk menginap di hotel syariah. Alkohol atau babi tidak boleh disajikan di gerai makanan dan minuman di hotel, dan tentu saja tidak boleh ada minibar berisikan minuman haram di kamar. Minibar hanya boleh menyediakan makanan dalam kemasan dan minuman yang berlogo halal resmi. ${ }^{8}$

Hal ini sebenarnya adalah penyesuaian pada prinsip umum muamalah dalam ekonomi Islam yaitu (1) tidak memproduksi, memperdagangkan, menyediakan, atau menyewakan produk atau jasa yang secara keseluruhan maupun sebagiannya dilarang dalam ketentuan syariah. Seperti dalam hal makanan, mengandung unsur babi, minuman beralkohol, perjudian, perzinaan, dan yang semacam itu; (2) tidak mengandung unsur kezhaliman, kemungkaran, kemaksiatan maupun kesesatan yang terlarang dalam kaidah syariah, baik secara langsung maupun tidak langsung; (3) tidak ada pula unsur penipuan, kecurangan, kebohongan, ketidak-jelasan, resiko yang berlebihan dan membahayakan; dan (4) ada komitmen menyeluruh dan konsekuen dalam menjalankan perjanjian yang disepakati antar pihak-pihak terkait, yang kemudian dituangkan kedalam persyaratan agar bisnis hotel menjadi berlabel syariah. ${ }^{?}$

Pengembangan hotel dan operasi bisnis hotel juga harus dibiayai melalui pengaturan keuangan Islam untuk sepenuhnya menghormati prinsip keuangan syariah. ${ }^{10}$ Tentu saja ini berarti pada hotel syariah, tidak diperkenankan menggunakan pembayaran dengan kartu debit dan kredit dari bank konvensional. Hal ini juga berlaku pada manajemen bisnis hotel syariah yang harus bekerjasama dengan bank-bank syariah sebagai

http://www.kemenpar.go.id/userfiles/LAMPIRAN TENTANG PEDOMAN HOTEL SYARIAH.pdf.

9 Anwar Basalamah, "Hadirnya Kemasan Syariah Dalam Bisnis Perhotelan Di Tanah Air," Binus Business Review 2, no. 2 (2011): 763-69.

10 "Lampiran Peraturan Menteri Pariwisata Dan Ekonomi Kreatif Republik Indonesia Nomor 2 Tahun 2014 Tentang Pedoman Penyelenggaraan Usaha Hotel Syariah Kriteria Mutlak Dan Kriteria Tidak Mutlak Usaha Hotel Syariah A. Kriteria Hotel Syariah Hilal 1," Pub. L. No. 2, Kementrian Pariwisata dan Ekonomi Kreatif Republik Indonesia (2014), http://www.kemenpar.go.id/userfiles/LAMPIRAN TENTANG PEDOMAN HOTEL SYARIAH.pdf. 
afiliasi perusahaan keuangan dalam bisnisnya. Selain itu hotel syariah juga wajib menyisihkan sebagian pendapatan untuk zakat yang disalurkan melalui lembaga zakat resmi.

B. Peluang dan Tantangan Bisnis Hotel Syariah pada Masyarakat Kosmopolitan

Kosmopolitan berasal dari kata "kosmo" yang berarti universe atau dunia dan kata "polis" yang berarti kota. Dengan kata lain, manusia dapat hidup dalam dua lingkungan, yaitu kota dimana manusia tersebut tinggal dan di lingkup global dimana manusia menjadi bagiannya. Immanuel Kant mengungkapkan, "kosmopolitan sangat menjunjung tinggi moral di mana semua manusia harus memiliki saling pengertian." Seseorang yang memiliki pemikiran kosmopolitanisme dalam bentuk apapun disebut kosmpolitan atau kosmopolit. Sehingga kosmopolitanisme adalah ideologi yang menyatakan bahwa semua suku bangsa manusia merupakan satu komunitas tunggal yang memiliki moralitas yang sama. ${ }^{11}$

Kosmopolitanisme peradaban Islam muncul dalam sejumlah unsur dominan, seperti hilangnya batasan etnis, kuatnya pluralitas budaya dan heteroginitas politik. Kosmopolitanisme itu bahkan menampakkan diri dalam unsur dominan yang menakjubkan, yakni kehidupan beragama selama berabadabad. Menurut Wahid, nilai-nilai moral Islam yang universal menampakkan diri dalam berbagai manifestasi ajaran-ajarannya, seperti hukum agama (fiqh), keimanan (tauhid), serta etika (akhlaq). Masyarakat Islam kosmopolitan ada sekelompok Muslim yang memahami ajaran-ajaran tersebut secara luas, sehingga mengesankan Islam sebagai agama yang bersifat internasional dan bisa berbaur dengan budaya lokal. Dalam pandangan Wahid, ajaran-ajaran Islam tersebut memiliki kepedulian kepada unsur-unsur utama kemanusiaan yang diimbangi oleh kearifan yang muncul dari keterbukaan peradaban Islam sendiri. Kosmopolitanisme peradaban Islam mencapai titik optimalnya jika tercapai keseimbangan antara kecenderungan normatif kaum Muslimin dan kebebasan berpikir semua warga masyarakat, termasuk mereka yang non Muslim. Situasi seperti itu

${ }^{11}$ Lunyka Adelia Pertiwi, “Analisa Perspektif Islam Dan Kosmopolitanisme Terhadap Upaya Global Penanganan Pengungsi Suriah," JISIERA: THE JOURNAL OF ISLAMIC STUDIES AND INTERNATIONAL RELATIONS 1, no. Agustus (2016): 1-13, http://jisiera.insiera.org/index.php/jisiera/article/view /012016/2. disebut sebagai kosmopolitanisme yang kreatif, yang memungkinkan pencarian sisi-sisi paling tidak masuk akal dari kebenaran yang ingin dicari dan ditemukan. ${ }^{12}$

Dengan semakin pesatnya perkembangan perbankan syariah dan lembaga keuangan syariah di seluruh dunia, dapat kita katakan kosmopolitanisme Islam juga semakin menjadi kosmopolitanisme yang kreatif. Kini Islam tidak lagi hanya dipandang sebagai sebuah ajaran, tetapi bisa membuktikan bahwa Islam memang bersifat universal dan dapat diterapkan dalam bidang apa pun dan berkembang. Perkembangan ini tidak hanya berhenti pada syariah finance namun kini sudah merambah bidang industri. Salah satunya adalah industri perhotelan syariah.

Menurut Anwar, hotel syariah merupakan suatu jasa akomodasi yang beroperasi dan menganut prinsip-prinsip pedoman ajaran Islam. Secara operasionalnya, pelayanan yang diberikan di hotel syariah tentunya hampir menyerupai hotel konvensional atau nonsyariah pada umumnya. Namun konsep hotel ini menyeimbangkan aspek-aspek spiritual Islam yang berlaku didalam pengelolaan dan pengoperasiannya. Dalam pandangan awam, hotel syariah kadang masih dianggap sebagai suatu bisnis usaha jasa yang hanya dikhususkan untuk pasar Muslim. Padahal hotel syariah merupakan akomodasi yang juga beroperasi 24 jam dan terbuka untuk segala kalangan, baik masyarakat Muslim maupun nonMuslim. ${ }^{13}$ Dari pandangan tersebut kita akan membahas peluang dan tantangannya dari bisnis hotel syariah pada masyarakat kosmopolitan.

\section{Jumlah Penduduk Muslim}

Meski umat Kristen tetap menjadi kelompok agama terbesar di dunia pada tahun 2015, membentuk hampir sepertiga (31\%) dari 7,3 miliar penduduk Bumi, menurut analisis demografi Pew Research Center terbaru, tetapi umat Islam ada pada kelompok terbesar kedua di dunia. Secara global, kelompok Muslim memiliki 1,8 miliar orang, atau $24 \%$ dari populasi dunia, diikuti oleh 'tidak beragama' (16\%), Hindu (15\%) dan Buddha (7\%). ${ }^{14}$ Sementara populasi

12 Abdurrahman Wahid, Islam Kosmopolitan, Nilai-Nilai Indonesia \&amp; Transformasi Kebudayaan, ed. Agus Maftuh Abegebriel, 1st ed. (Jakarta: The Wahid Institute, 2007).

${ }^{13}$ Basalamah, "Hadirnya Kemasan Syariah Dalam Bisnis Perhotelan Di Tanah Air."

14 Conrad Hackett and David Mcclendon, "World's Largest Religion by Population Is Still Christianity | Pew Research Center," Pew Research Center, 2017, 
dunia diproyeksikan tumbuh $32 \%$ dalam beberapa dekade mendatang, jumlah Muslim diperkirakan akan meningkat sebesar 70\% dari 1,8 miliar pada tahun 2015 menjadi hampir 3 miliar pada 2060. Pada 2015, umat Muslim mencapai 24,1\% dari global populasi. Empat puluh lima tahun kemudian, Muslim diproyeksikan akan membuat lebih dari tiga dari sepuluh orang di dunia $(31,1 \%) .{ }^{15}$

Muslim merupakan mayoritas penduduk di 49 negara di seluruh dunia. Negara dengan jumlah terbesar (sekitar 209 juta) adalah Indonesia, di mana $87,2 \%$ penduduk mengidentifikasi diri mereka sebagai Muslim. India memiliki populasi Muslim terbesar kedua di dunia dalam jumlah mentah (sekitar 176 juta), meskipun umat Islam hanya mencakup $14,4 \%$ dari total populasi India. Namun, kawasan Timur Tengah-Afrika Utara memiliki konsentrasi Muslim tertinggi di kawasan mana pun di dunia: $93 \%$ dari sekitar 341 juta penduduknya adalah Muslim, dibandingkan dengan 30\% di sub-Sahara Afrika dan 24\% di Asia-Pasifik. ${ }^{16}$ Dari data tersebut kita dapat melihat bahwa pasar Muslim dunia sangat besar dan akan semakin besar. Hal ini tentu saja membawa angin segar kepada pelaku bisnis di industri syariah. Artinya akan ada banyak peluang dari pangsa pasar Muslim dunia.

Wiwiek Sisto Widayat, Direktur Eksekutif Bank Indonesia, dalam seminar yang merupakan rangkaian acara dari Annual Meeting IMF-World Bank di Lombok, Nusa Tenggara Barat, juga mengatakan wisata syariah menjadi salah satu bidang yang sangat potensial dikembangkan mengingat banyaknya umat Islam yang tersebar di seluruh dunia. ${ }^{17}$ Namun kemudian tantangan

http://www.pewresearch.org/fact-

tank/2017/04/05/christians-remain-worlds-largest-

religious-group-but-they-are-declining-in-europe/.

15 Michael Lipka and Conrad Hackett, "Why Muslims Are the World's Fastest-Growing Religious Group," Pew Research Center, 2017, http://www.pewresearch.org/fact-

tank/2017/04/06/why-Muslims-are-the-worlds-fastestgrowing-religious-group/.

16 Drew Desilver and David Masci, "World Muslim Population More Widespread than You Might Think," Pew Research Center, 2017, http://www.pewresearch.org/facttank/2017/01/31/worlds-Muslim-population-morewidespread-than-you-might-think/. yang muncul adalah dari negara-negara mayoritas penduduk Muslim di dunia, hanya masyarakat di kawasan Timur Tengah yang paling sering melancong dan menginap di hotel-hotel. Dari laporan Kementerian Pariwisata Indonesia misalnya, melaporkan bahwa negara yang paling sering berkunjung ke Nusantara adalah dari Tiongkok, Eropa, Australia, Singapura, dan India, sedangkan Malaysia berada di urutan keenam dan Timur Tengah berada di urutan ketigabelas. ${ }^{18}$

Meski begitu, Timur Tengah masih lah menjadi potensi pasar halal tourism di masa depan yang keberhasilannya terletak pada rencana promosi dan pemasaran yang efektif. Timur Tengah sangat berpotensi untuk berbelanja dengan nilai yang tinggi. Penduduk yang melakukan perjalanan ini rata- rata berusia 30-45 tahun, bepergian dengan kelompok besar/keluarga, maka strategi komunikasi pemasaran sebaiknya disesuaikan dengan karakteristik usia dan motivasi perjalanannya. Maka produkproduk yang harus dipromosikan oleh hotel syariah tidak hanya sekedar kamar atau tempat menginap, tetapi juga menyuguhkan paket wisata pendamping sesuai dengan pangsa pasar yang dituju. ${ }^{19}$

\section{Konsep Syariah}

Konsep syariah dalam industri perhotelan memang telah meningkat permintaannya, yang menyebabkan banyak pebisnis hotel global tertarik untuk menerapkan konsep syariah dan membuka hotel-hotel tersebut untuk menangkap pasar. Meskipun permintaan meningkat, masih banyak orang yang tidak sepenuhnya menyadari konsep syariah ini karena kesalahpahaman. Seperti yang disarankan oleh Huang, Qiu, Bai, \& Pray dalam Mahmud, pengetahuan dan informasi

17 Ahmad Baiquni, "Wisata Halal Berpotensi Kuatkan Ekonomi Indonesia | Travel.Dream.Co.Id," Travel Dream, 2018, https://travel.dream.co.id/news/wisatahalal-berperan-strategis-kuatkan-ekonomi-nasional1810174.html.

18 Puri Yuanita, "Turis Dari 5 Negara Ini Paling Banyak Kunjungi Indonesia | Travel.Dream.Co.Id," Travel Dream, 2018,

https://travel.dream.co.id/destination/turis-dari-5negara-ini-paling-banyak-kunjungi-indonesia-

180209r.html.

${ }^{19}$ Kurniawan Gilang Widagyo, “Analisis Pasar Pariwisata Halal Indonesia," The Journal of Taubidinomics 1, no. 1 (2015): 73-80. 
tentang konsep hotel syariah dapat mempengaruhi sikap pelanggan. Dengan demikian pelanggan harus mendapatkan informasi tentang konsep syariah untuk mendapatkan lebih banyak pengetahuan. Ini dapat dilakukan melalui berbagai materi pemasaran seperti buku, majalah, media dan banyak lagi cara-cara pemasaran lainnya. Di sisi lain, pelaku industri hotel syariah juga harus bekerja sama untuk mendidik pelanggan dengan memberi mereka informasi tentang konsep untuk mencegah terjadinya salah tafsir. ${ }^{20}$

Penelitian Azsyanti dan Salamiah kepada wisatawan lokal non-Muslim di Malaysia misalnya, menunjukkan bahwa kesadaran akan konsep dan praktik yang terkait dengan syariah bervariasi secara signifikan. Pelanggan non-Muslim pada dasarnya tidak begitu jelas mengerti tentang fitur konsep yang sesuai dengan syariah. Mereka tidak menyadari praktik-praktik apa yang sesuai dengan syariah. Faktor-faktor yang berkontribusi terhadap tingkat kesadaran rendah dari pelanggan nonMuslim lokal dari konsep dan praktik Syariah adalah karena kurangnya iklan di Malaysia untuk mempromosikan konsep ini dibandingkan dengan inisiatif pemerintah dalam mempromosikan kesadaran taat syariah kepada orang Malaysia. Faktor lain mungkin juga disebabkan oleh fakta bahwa konsep Sharia Compliance masih baru di Malaysia, dan hanya beberapa hotel yang telah mempraktikkannya. ${ }^{21}$

Padahal konsep syariah yang dipakai di hotel-hotel bersertifikat syariah tidak jauh beda pada nilai-nilai yang diyakini dan dianggap penting oleh masyarakat kosmopolitan dunia. Komunitas kosmopolitan saat ini didasarkan pada moralitas inklusif, hubungan ekonomi bersama, atau struktur politik yang mencakup berbagi bangsa. Dalam komunitas kosmopolitan, orang-orang dari berbagai tempat (misalnya negara-bangsa) membentuk hubungan yang saling

${ }^{20}$ Haji Mahmud bin Haji Mohamed, "Promoting Islamic Tourism in Brunei: Through Customers Understanding Towards the Syariah Compliant Hotel Concepts" (University of Nottingham, 2014).

21 Azsyanti Ibrahim and Salamiah A Jamal, "A Case Study of Local Non-Muslim Guest Awareness towards Syariah-Compliance in Grand BlueWave Shah Alam," TE AM Journal of Hospitality and Tourism 13, no. 1 (2016): 55-64. menghargai. Kwame Anthony Appiah pernah memaparkan komunitas kosmopolitan adalah ketika orang-orang dari berbagai bidang membina hubungan yang saling menghargai meski memiliki kepercayaan yang berbeda (baik agama, politik, bangsa mau pun negara).22

Konsep kosmopolitan sebetulnya dapat dipahami melalui prinsip Islam dalam memandang manusia. Dalam surat An-Nahl ayat 90 Allah SWT, yang artinya:

'sesunggubnya Allah menyurub (kamu) berlaku adil dan berbuat kebajikan, memberi kepada kaum kerabat, dan Allah melarang dari perbuatan keji, kemungkaran dan permusuban. Dia memberi pengajaran kepadamu agar kamu dapat mengambil pelajaran'.

Nilai-nilai yang ada pada hotel syariah sebenarnya termasuk kedalam universalisme moral yang dianggap baik tidak hanya pada agama Islam saja, tetapi sudah masuk kedalam nilai yang dapat diterima oleh komunitas kosmopolitan dunia. Misalnya dengan adanya hotel syariah, tindakan asusila, perselingkuhan, mabuk-mabukan, dan spa plus-plus yang melekat erat pada hotel konvensional membuat masyarakat resah dan tidak nyaman bisa diminimalisir. Masyarakat kosmopolitan menganggap bahwa setiap manusia memilki tugas dan kewajiban yang sama di manapun ia berada. Karena itu, sebagai manusia, setiap orang dituntut untuk hidup berperilaku dan bertindak sebagai manusia, sehingga ia dapat dianggap hidup baik secara moral. Sebagai paham etis, universalisme mengakui dan menjunjung tinggi kemanusiaan. Meskipun sebagai sebuah konsep bernada abstrak, bagi mereka yang menganut paham universalisme kemanusiaan merupakan hal nyata. Kemanusiaan pantas dijaga, dilindungi terhadap serangan, dibela, dan dikembangkan agar mencapai kesempurnaan dalam pemenuhannya. ${ }^{23}$

Hanya saja kemudian yang menjadi penghalang adalah kurangnya informasi dan sosialisasi sehingga masih banyak yang

22 Kwame Anthony Appiah, "Cosmopolitan Patriots," Critical Inquiry 23, no. 3 (1997): 617-39, http://appiah.net/wpcontent/uploads/2010/10/Cosmopolitan-Patriots.Critical-Inquiry-23.3.-1997.pdf.

23 A. Mangunhardjana, Isme-Isme Dalam Etika Dari A Sampai Z (Yogyakarta: Kanisius, 1997). 224-227. 
kurang paham dengan konsep syariah pada hotel syariah. Hal ini bisa disebabkan oleh informasi mengenai standarisasi pembentukan hotel syariah sendiri masih belum tergambar jelas di mata publik, khususnya bagi para pelaku bisnis hotel. Banyak pengusaha hotel syariah yang masih rancu terhadap legalitas penetapan syariah yang harus dimiliki sebagai acuan. Tidak bisa dipungkiri jika beberapa pemilik hotel syariah memberanikan diri mengoperasikan usahanya hanya atas dasar pemahaman ke Islaman pribadi mereka sendiri. Sehingga kualitas pengelolaan dan pengoperasiaannya kadang masih belum maksimal. ${ }^{24}$

Penelitian Ahmat di Malaysia menyatakan bahwa penerapan praktikpraktik sebuah hotel syariah tidak semudah yang dipikirkan terutama ketika berhadapan dengan tamu non-Muslim karena berbagai latar belakang tamu hotel memeluk tingkat pemahaman dan penerimaan yang berbeda. Dalam konteks ini, latar belakang multi-rasial Melayu, Cina, India, dan ras lain dianggap memiliki kedudukan mereka sendiri dan penerimaan pada praktik-praktik syariah meskipun Malaysia menyatakan dirinya sebagai negara Islam. Tidak hanya di kalangan non-Muslim, komunitas Muslim juga akan memiliki tingkat penerimaan yang berbeda. ${ }^{25}$

Senada dengan itu Ulfa dengan penelitiannya di hotel Arini Syariah Surakarta menyatakan bahwa tidak adanya sertifikat dari Dewan Nasional Syariah Majelis Ulama Indonesia yang menjadi bukti legal-formal sebagai hotel syariah menjadi salah satu hambatan besar bagi berjalannya bisnis hotel syariah. Kemudian standar kualifikasi dan kompetensi karyawan yang masih rendah (SKNI) juga berpengaruh terhadap kualitas pelayanan kepada pelanggan. Menurut Ulfa,

\footnotetext{
${ }^{24}$ Basalamah, "Hadirnya Kemasan Syariah Dalam Bisnis Perhotelan Di Tanah Air."

25 Nur' Hidayah Che Ahmat, Ahmad Hidayat Ahmad Ridzuan, and Mohd Salehuddin Mohd Zahari, "Dry Hotel and Syariah Compliant Practices: Concepts, Challenges and Reality in Malaysia," in International Conference on Innovation, Management and Technology Research (Malacca: ResearchGate, 2012), 107-11.

${ }^{26}$ Maria Ulfa, "Analisis Penerapan Prinsip Syariah Di Hotel Arini Syariah Surakarta” (Surabaya, 2012).

${ }^{27}$ Eka Mariyanti, Puti Embun Sari, and Siska Lusia Putri, "Persepsi Konsumen Terhadap Minat Berkunjung Pada Hotel Syariah Di Kota Padang," Menara Ekonomi IV, no. 1 (2018): 9-17.
}

pandangan miring masyarakat terhadap sebuah hotel sebagai tempat yang menyediakan layanan jasa penginapan yang memiliki citra buruk masih menghantui bisnis hotel syariah. Kemudian perkembangan dan dinamika dalam dunia bisnis menuntut pelaku bisnis untuk senantiasa berkompetisi, yang terkadang dapat menjadikan mereka lupa diri sehingga menerjang aturan-aturan, etika dan moral yang seharusnya dijaga oleh pelaku binis hotel syariah. ${ }^{26}$

Padahal konsep syariah ini lah daya jual yang dimiliki oleh hotel syariah. Sebagaimana hasil penelitian Miriyanti, Sari, dan Putri di kota Padang, bahwa persepsi nilai berpengaruh terhadap minat berkunjung, dari beberapa pernyataan yang telah diajukan kepada tamu hotel syariah yang ada dikota Padang bahwasanya tamu sangat mementingkan nilai-nilai yang melekat pada hotel syariah. ${ }^{27}$ Ini juga sejalan dengan penelitian Nasrullah, di mana Islamic Branding sangat berpengaruh terhadap keputusan konsumen untuk membeli suatu produk. ${ }^{28}$ Penelitian dari Ratna dan Salma pada hotel syariah di Surabaya juga menunjukkan hasil yang sama, yaitu dengan penyediaan layanan yang sesuai dengan syariah Islam maka akan mempengaruhi kepuasan pelanggan hotel syariah. ${ }^{29}$

Saleh dalam penelitiannya di kota Bandung menyatakan seratus persen mereka yang menginap di hotel syariah menyatakan bahwa mereka merasa lebih nyaman memilih hotel yang melarang pasangan yang bukan muhrim untuk bermalam di satu kamar. ${ }^{30}$ Ada pun menurut penelitian dari Rahardi dan Wiliasih, semakin tinggi citra hotel yang baik maka konsumen akan lebih cenderung memilih hotel syariah. ${ }^{31}$ Dari hasil penelitian yang sudah penulis jabarkan, artinya konsep

${ }^{28}$ Muhammad Nasrullah, "Islamic Branding, Religiusitas Dan Keputusan Konsumen Terhadap Produk," Jurnal Hukum Islam 13, no. 2 (2015): 79-87.

29 Fitria Solahika Salma and Ririn Tri Ratnasari, "Pengaruh Kualitas Jasa Perspektif Islam Terhadap Kepuasan Dan Loyatitas Pelanggan Hotel Grand Kalimas Di Surabaya," JESTT 2, no. 4 (2015): 322-39.

30 Sri Sundari Saleh, "Willingness To Pay (WTP) Dan Faktor-Faktor Yang Memengaruhi Konsumen Dalam Memilih Hotel Syariah Di Kota Bandung" (Institut Pertanian Bogor, 2017).

${ }^{31}$ N. Rahardi and R. Wiliasih, "Analisis Faktor-Faktor Yang Mempengaruhi Preferensi Konsumen Terhadap Hotel Syariah," Jurnal Syarikah 2, no. 1 (2016): 180-92. 
syariah bukan hanya harus diterapkan secara maksimal, tetapi juga konsumen harus tahu apa itu konsep syariah pada sebuah hotel. Tantangan yang timbul adalah bagaimana pebisnis hotel syariah mengedukasi masyarakat luas agar mengetahui bahwa hotel miliknya adalah hotel bercitra baik dan berkonsep syariah. Maka hal yang harus dilakukan adalah melakukan promosi besarbesaran agar para konsumen tahu apa itu konsep syariah pada hotel syariah.

3. Access, Communication, Environment, dan Service

Sebagai kriteria penilaian dalam Global Muslim Travel Indeks, access, communication, environment, dan service, menjadi penting untuk kita bahas dalam hal peluang dan tantangan pada bisnis hotel syariah. Akses di sini selain lokasi hotel syariah, termasuk juga dengan harga yang ditawarkan oleh hotel syariah. Meskipun hotel sudah menerapkan konsepkonsep syariah tetapi harga merupakan faktor penting yang diperhatikan oleh para konsumen ketika memilih tempat untuk menginap. Penelitian dari Mariyanti, Sari dan Putri menyatakan bahwa persepsi harga berpengaruh terhadap minat berkunjung. Persepsi harga menjadi sebuah penilaian konsumen tentang perbandingan besarnya pengorbanan dengan apa yang akan didapatkan dari produk dan jasa. Persepsi harga sering diidentikkan dengan persepsi kualitas dan persepsi biaya yang dikeluarkan untuk memperoleh produk. Persepsi harga dilihat dari tiga indikator yaitu harga yang terjangkau, fasilitas yang tersedia dan lebih murah dari pesaing kondisi hotel yang ada. ${ }^{32}$

Penetapan harga ini bergantung pada beban biaya dan keuntungan yang ingin didapatkan. Dalam Islam pengambilan keuntungan atau laba memang tidak dibatasi tetapi diharapkan pada range kewajaran. Islam menganjurkan agar para pedagang tidak berlebihan dalam mengambil laba. Ali bin Thalib r.a. berkata, "Wahai para saudagar! Ambil lah (laba) yang pantas maka kamu akan selamat (berhasil) dan jangan

32 Mariyanti, Sari, and Putri, "Persepsi Konsumen Terhadap Minat Berkunjung Pada Hotel Syariah Di Kota Padang."

33 Moh. Idil Ghufron, "Konsep Maslahah Maximizer Pada Hotel Syariah Perspektif Etika Bisnis Islam," Jurnal Islam Nusantara 01, no. 02 (2017): 131-43.

${ }^{34}$ Saleh, "Willingness To Pay (WTP) Dan Faktor-Faktor Yang Memengaruhi Konsumen Dalam Memilih Hotel Syariah Di Kota Bandung." kamu menolak laba yang kecil karena itu akan menghalangi kamu dari mendapatkan (laba) yang banyak." Pernyataan ini menjelaskan bahwa batasan laba ideal (yang pantas dan wajar) dapat dilakukan dengan merendahkan harga. Keadaan ini sering menimbulkan bertambahan jumlah barang dan meningkatnya peranan uang dan pada gilirannya akan membawa pada pertambahan laba. ${ }^{33}$

Oleh karena itu dalam hal bisnis, meski pun memakai konsep syariah, namun tetap harus mementingkan persaingan harga yang wajar, baik persaingan antara hotel-hotel syariah lainnya atau pun dengan hotel-hotel konvensional. Karena pada akhirnya jika harga mahal, meski pun syariah, konsumen akan mempertimbangkan berulang kali jika tidak sesuai dengan budget mereka. Namun, menurut Saleh dalam hasil penelitiannya, para konsumen hotel syariah mengatakan bahwa harga hanya 10\% pengaruhnya pada alasan mereka menginap. Alasan yang paling mempengaruhi adalah fasilitas dan disusul oleh pelayanan atau service. Sedangkan lokasi hanya berpengaruh 13\% terhadap konsumen hotel syariah. Hal ini karena mereka memiliki kebersediaan untuk membayar di atas ratarata untuk hotel syariah adalah mereka yang sudah paham dan ingin menerapkan lifestyle sesuai syariah sampai kepada hotel yang mereka tinggali. ${ }^{34}$

Sejalan dengan itu, penelitian Hayati yang menyatakan bahwa keinginan untuk menginap di hotel syariah adalah karena faktor lokasi, atmosfer hotel syariah, citra hotel syariah, budaya, fasilitas, dan keamanan. ${ }^{35}$ Penelitian Rahardi dan Wiliasih juga mengemukakan bahwa semakin strategis lokasi maka konsumen akan lebih cenderung memilih hotel syariah karena lokasi yang strategis akan berpengaruh pada pertimbangan konsumen untuk memilih hotel syariah. ${ }^{36}$ Maka access yang lebih berpengaruh pada industri hotel syariah adalah lokasi ketimbang harga. Dengan

35 Asfarina Hayati, "Faktor Yang Mempengaruhi Keputusan Konsumen Muslim Memilih Hotel Syariah Grand Kalimas Surabaya” (Universitas Airlangga, 2014). 36 Rahardi and Wiliasih, "Analisis Faktor-Faktor Yang Mempengaruhi Preferensi Konsumen Terhadap Hotel Syariah." 
catatan konsumen sudah terlebih dahulu mengerti konsep syariah pada sebuah hotel. ${ }^{37}$

Kemudian communication, environment dan service akan penulis bahas sebagai fasilitas, pelayanan, dan SDM yang bekerja di hotel syariah. Fasilitas mempengaruhi sebesar 33\% kepada keinginan konsumen untuk bermalam di hotel syariah. Penelitian Saleh juga menunjukkan bahwa hotel dengan fasilitas yang lebih lengkap (seperti adanya peralatan shalat di setiap kamar, adanya informasi mengenai waktu shalat dan ketersediaan peralatan bersuci) memiliki kecenderungan dipilih oleh konsumen Muslim lebih besar dibandingkan hotel konvensional..$^{38}$ Semakin tinggi fasilitas hotel syariah maka konsumen akan lebih berpeluang memilih hotel syariah, karena tingkat fasilitas yang tinggi akan berpengaruh pada pertimbangan konsumen untuk memilih hotel syariah, begitulah hasil penelitian dari Rahardi dan Wiliasih. ${ }^{39}$ Ini juga sesuai dengan penelitian dari Mariyanti, Sari, dan Putri, di mana masyarakat Padang akan semakin memilih hotel syariah jika fasilitasnya semakin baik..$^{40}$

Penataan ruangan yang baik dan nyaman, petugas selalu berpakaian rapi dan berpenampilan sopan, mempunyai kemampuan yang baik dalam menjawab semua pertanyaan dari pelanggan/konsumen, dapat melayani dengan cermat dan teliti, merupakan kualitas pelayanan yang diharapkan ada pada hotel syariah. Wijiatno dalam penelitiannya menyebutkan bahwa tingkat pelayanan berpengaruh sangat signifikan terhadap keputusan konsumen dalam memilih hotel syariah sebagai tempat menginap. ${ }^{41}$ Pelayanan menurut Saleh berpengaruh sebesar 30\% terhadap keinginan konsumen untuk membeli produk jasa hotel syariah.

\footnotetext{
${ }^{37}$ Andri Wijiatmoko, “Analisis Pengaruh Harga, Kualitas Pelayanan, Dan Lokasi Terhadap Keputusan Pembelian Hotel Syariah (Studi Pada Pelanggan Hotel Syariah Di Surakarta)" (Surakarta, 2016).

38 Saleh, "Willingness To Pay (WTP) Dan Faktor-Faktor Yang Memengaruhi Konsumen Dalam Memilih Hotel Syariah Di Kota Bandung."

39 Rahardi and Wiliasih, "Analisis Faktor-Faktor Yang Mempengaruhi Preferensi Konsumen Terhadap Hotel Syariah.”

40 Mariyanti, Sari, and Putri, "Persepsi Konsumen Terhadap Minat Berkunjung Pada Hotel Syariah Di Kota Padang."
}

Namun menurut responden penelitian Saleh, konsumen hotel syariah merasa bahwa sikap yang diberikan oleh karyawan hotel syariah tidak berbeda jauh dengan sikap karyawan di hotel konvensional. ${ }^{42}$ Padahal menurut Ratnasari dan Salma, sesuai dengan hasil penelitian mereka, kualitas jasa perspektif Islam merupakan faktor dalam membentuk kepuasan dan loyalitas pelanggan di Surabaya. ${ }^{43}$ Oleh karena itu, harusnya agar bisnis hotel syariah lebih berkembang, maka yang harus dilakukan adalah menjaga kualitas pelayanan sesuai dengan kriteria pelayanan jasa Islam.

Dimensi kualitas jasa perspektif Islam pertama kali diperkenalkan oleh Othman dan Owen yang digunakan untuk mengukur kualitas jasa. Dimensi tersebut adalah CARTER model, yaitu Compliance, Assurance, Reliability, Tangible, Empatby dan Responsiveness (CARTER). ${ }^{44}$ Dimensi CARTER yang dijelaskan dalam konsep Islam adalah sebagai berikut:

a. Compliance (kepatuhan) adalah kepatuhan terhadap aturan atau hukum-hukum yang ditetapkan dalam Alquran dan sunah. Pemenuhan kriteria ini menurut Othman dan Owen ialah pada hukum dan prinsipprinsip Islam. Kemudian tidak ada bunga yang dibayarkan atau diambil dari konsumen. Termasuk juga penyediaan produk dan layanan Islami. Jika konsumen menggunakan fasilitas keuangan berupa kredit maka tidak boleh mengambil bunga atasnya. Investasi bagi pebisnis hotel syariah harus lah dalam bentuk bagi hasil. Hal ini harus melibatkan karyawan yang mengetahui dan menjalankan bisnis sesuai dengan peraturan yang berlaku 45

b. Assurance (jaminan) adalah pengetahuan, dan kesopanan karyawan dan

41 Wijiatmoko, "Analisis Pengaruh Harga, Kualitas Pelayanan, Dan Lokasi Terhadap Keputusan Pembelian Hotel Syariah (Studi Pada Pelanggan Hotel Syariah Di Surakarta)."

${ }^{42}$ Saleh, "Willingness To Pay (WTP) Dan Faktor-Faktor Yang Memengaruhi Konsumen Dalam Memilih Hotel Syariah Di Kota Bandung."

43 Salma and Ratnasari, "Pengaruh Kualitas Jasa Perspektif Islam Terhadap Kepuasan Dan Loyatitas Pelanggan Hotel Grand Kalimas Di Surabaya."

${ }^{44}$ Salma and Ratnasari.

45 Abdul Qawi Othman and Lynn Owen, “Adopting and Measuring Customer Service Quality (SQ) in Islamic Banks: A Case Study in Kuwait Finance House," 
kemampuan serta kemahiran mereka untuk menyampaikan kepercayaan dan keyakinan. Pengetahuan dan kemahiran atas suatu produk hanya akan diperoleh dari sebuah proses belajar yang tekun dan bersungguh-sungguh. Ini juga termasuk komunikasi verbal dan tertulis antara staf dan pelanggan. Kesopanan dan staf yang ramah menjadi hal yang penting untuk diperhatikan agar layanan menjadi semakin baik. Kenyamanan interior, kemudahan akses ke informasi, dan tim manajemen yang berpengetahuan dan berpengalaman akan menjadi jaminan kenyamanan layanan. Salah satunya dengan cara meningkatkan knowledge management yang dimiliki karyawan dengan tujuan meningkatkan competitive advantage. 46

c. Responsiveness (daya tanggap) adalah kesediaan untuk membantu pelanggan dan memberikan layanan yang cepat. Ini merupakan bagian dari profesionalitas. Daya tanggap ini berkaitan dengan pengetahuan tentang bisnis pelayanan dan kesadaran untuk selalu bersedia membantu konsumen serta bagaimana para staf memperlakukan pelanggan. Ketersediaan sarana prasarana yang mempermudah pelanggan, layanan yang cepat dan efisien, serta dalam perkembangan teknologi dewasa ini admin website dan media sosial milik hotel syariah harus selalu up-date dan cepat respon. Salah satu caranya maka karyawan bekerja harus ditempatkan sesuai dengan keahliannya dan karyawan harus cepat beradaptasi dengan budaya kerja yang berlaku. ${ }^{47}$

d. Tangible (bukti fisik) merupakan tampilan fisik yang akan menunjukkan identitas organisasi sekaligus faktor pendorong munculnya persepsi awal pelanggan terhadap suatu organisasi jasa. Dalam hal ini misalnya adalah bagaimana tampilan hotel yang memiliki design yang menunjukkan prinsip-prinsip keIslaman. Begitu pula dengan tampilan dari para staf yang menutup aurat dan terlihat identitas syariahnya. ${ }^{48}$

e. Empathy (empati) sebuah organisasi jasa syariah harus senantiasa memberikan perhatian khusus terhadap masingmasing pelanggannya yang ditunjukkan dengan sikap komunikatif yang diiringi kepahaman tentang kebutuhan pelanggan. Karyawan harus memiliki keterampilan penunjang sehingga staff dapat melakukan tugasnya dengan benar konsisten, penuh motivasi \& disiplin.

f. Reliability (kehandalan) adalah kemampuan untuk memberikan kenyamanan dalam waktu singkat untuk layanan kapan saja. Berbagai macam produk dan layanan yang disediakan harus lah benar-benar dikuasai oleh para staf, sehingga kita bisa mengatakan para staf itu sungguh handal dalam pekerjaannya. Selain itu, kita bisa melihat kehandalan seseorang pada bisnis hotel syariah saat mereka cekatan memberikan layanan meskipun dalam musim-musim liburan yang penuh dengan konsumen. Karyawan harus memiliki segala keterampilan sehingga staff dapat melakukan tugas pokoknya. ${ }^{49}$

Saat ini manusia sudah menuju berkewarganegaraan dunia (world citizenship) dalam masyarakat yang kosmopolis, lalu berhadapan dengan kemajuan sains dan teknologi yang benar-benar berbeda dan lebih canggih, perkembangan industrialisasi yang semakin pesat, dan ini merupakan hal yang masuk akal secara sosiologis. Peluang besar dalam industri bisnis hotel syariah pada akhirnya tidak akan bisa diraih jika tantangan-tantangan tidak ditaklukkan. Marilah kita renungkan pernyataan dari Karl Mannheim yang sangat relevan berikut ini:

"One can understand the
contemporary world in its rapid
change only if one learns to think
sociologically, if one is capable of
understanding changes in ways of
human behavior by reference to the
changing conditions of society. This,
however, also requires acquaintance

48 Salma and Ratnasari, "Pengaruh Kualitas Jasa Perspektif Islam Terhadap Kepuasan Dan Loyatitas Pelanggan Hotel Grand Kalimas Di Surabaya.”

49 AbdulQawi Othman and Lynn Owen, "Adopting and Measuring Customer Service Quality (SQ) in Islamic Banks: A Case Study in Kuwait Finance House."

\footnotetext{
International Journal of Islamic Financial Services 3, no. (2001),

http:/ / citeseerx.ist.psu.edu/viewdoc/download?doi=1 0.1.1.201.1893\&rep=rep1\&type $=$ pdf.

46 AbdulQawi Othman and Lynn Owen.

47 AbdulQawi Othman and Lynn Owen.
} 
with recent findings in psychology

and philosophy". 50

\section{Penutup}

Sebagai industri baru di bidang syariah, bisnis hotel syariah mempunyai peluang-peluang di dalam masyarakat kosmopolitan. Jumlah penduduk Muslim di seluruh dunia yang semakin pesat perkembangannya menjadi kesempatan pangsa pasar hotel syariah yang paling utama. Kemudian konsep syariah yang ditawarkan sebuah hotel syariah sangat menjunjung tinggi nilai-nilai moralitas yang dipegang oleh masyarakat kosmopolitan sebagai bagian dari universalisme moral.

Namun tentu saja terdapat tantangantantangan yang harus dihadapi oleh para pelaku bisnis hotel syariah. Penduduk dunia yang beragama Islam memang banyak tetapi yang paling sering melakukan kegiatan traveling bukan berasal dari negara mayoritas Muslim. Sehingga promosi dan pengenalan konsep syariah terhadap mereka yang tidak beragama Islam pun harus dilakukan lebih. Penawaran produk yang termasuk bagian dari penginapan seperti kegiatan wisata dan fasilitasfasilitas tambahan harus menjadi bagian dari promosi manajemen hotel syariah. Selain itu, agar hotel syariah memiliki pelayanan yang prima dan benar-benar menerapkan konsep syariah dengan baik, para pegawai atau staf hendaknya diberikan pelatihan-pelatihan mengenai pengetahuan tentang syariah serta kualiatas layanan yang sesuai dengan syariah.

\section{Daftar Pustaka}

AbdulQawi Othman, and Lynn Owen. "Adopting and Measuring Customer Service Quality (SQ) in Islamic Banks: A Case Study in Kuwait Finance House." International Journal of Islamic Financial Services 3, no. 1 (2001). http:/ / citeseerx.ist.psu.edu/viewdoc/downl oad?doi=10.1.1.201.1893\&rep=rep1\&type $=$ pdf.

Abdurrahman Wahid. Islam Kosmopolitan, Nilai-Nilai Indonesia \&amp; Transformasi Kebudayaan. Edited by Agus Maftuh Abegebriel. 1st ed. Jakarta: The Wahid Institute, 2007.

Ahmad Baiquni. "Wisata Halal Berpotensi Kuatkan Ekonomi Indonesia | Travel.Dream.Co.Id." Travel Dream, 2018. https://travel.dream.co.id/news/wisatahalal-berperan-strategis-kuatkan-ekonominasional-1810174.html.

\footnotetext{
${ }^{50}$ Hasan Bachtiar, Haeri Fadly, and Moh. Nurhakim,
} "Visi Kosmopolitanisme Islam Di Lingkungan Jaringan
Ahmat, Nur' Hidayah Che, Ahmad Hidayat Ahmad Ridzuan, and Mohd Salehuddin Mohd Zahari. "Dry Hotel and Syariah Compliant Practices: Concepts, Challenges and Reality in Malaysia." In International Conference on Innovation, Management and Technology Research, 107-11. Malacca: ResearchGate, 2012.

Ahyakudin. "Dampak Program Training Terhadap Peningkatan Keunggulan Kompetitif Perusahaan (Studi Kasus Pada Hotel Sofyan Inn Altama Syariah Pandegelang)." Syi'ar Iqtishadi Journal of Islamic Economics, Finance and Banking 2, no. 1 (2018): 59-79.

Bachtiar, Hasan, Haeri Fadly, and Moh. Nurhakim. "Visi Kosmopolitanisme Islam Di Lingkungan Jaringan Intelektual Muda Muhammadiyah." Teosofi: Jurnal Tasawuf Dan Pemikiran Islam 5, no. 2 (2015): 455-85.

Basalamah, Anwar. "Hadirnya Kemasan Syariah Dalam Bisnis Perhotelan Di Tanah Air." Binus Business Review 2, no. 2 (2011): 763-69.

Conrad Hackett, and David Mcclendon. 'World's Largest Religion by Population Is Still Christianity | Pew Research Center." Pew Research Center, 2017. http://www.pewresearch.org/facttank/2017/04/05/christians-remain-worldslargest-religious-group-but-they-aredeclining-in-europe/.

Drew Desilver, and David Masci. "World Muslim Population More Widespread than You Might Think." Pew Research Center, 2017. http://www.pewresearch.org/facttank/2017/01/31/worlds-Muslimpopulation-more-widespread-than-youmight-think/.

Fahruddin Ali Sabri. "Perkembangan Hotel Syariah Di Indonesia; Mengonsep Pariwisata Islami." KARSA XVIII, no. 2 (2010): 114-22. http://download.portalgaruda.org/article.ph p?article $=251050 \& v a l=6749 \&$ title.

Ghufron, Moh. Idil. "Konsep Maslahah Maximizer Pada Hotel Syariah Perspektif Etika Bisnis Islam." Jurnal Islam Nusantara 01, no. 02 (2017): 131-43.

Hayati, Asfarina. "Faktor Yang Mempengaruhi Keputusan Konsumen Muslim Memilih Hotel Syariah Grand Kalimas Surabaya." Universitas Airlangga, 2014.

Ibrahim, Azsyanti, and Salamiah A Jamal. "A Case Study of Local Non-Muslim Guest Awareness towards Syariah-Compliance in Grand BlueWave Shah Alam.” TEAM Journal

Intelektual Muda Muhammadiyah," Teosofi: Jurnal Tasawuf Dan Pemikiran Islam 5, no. 2 (2015): 455-85. 
of Hospitality and Tourism 13, no. 1 (2016): 5564.

Jaelani, Aan. "Halal Tourism Industry in Indonesia: Potential and Prospects." Munich Personal RePEc Archive, no. 3 January (2017): 1-22.

Kwame Anthony Appiah. "Cosmopolitan Patriots." Critical Inquiry 23, no. 3 (1997): 61739. http://appiah.net/wpcontent/uploads/2010/10/CosmopolitanPatriots.-Critical-Inquiry-23.3.-1997.pdf.

Lampiran Peraturan Menteri Pariwisata Dan Ekonomi Kreatif Republik Indonesia Nomor 2 Tahun 2014 Tentang Pedoman Penyelenggaraan Usaha Hotel Syariah Kriteria Mutlak Dan Kriteria Tidak Mutlak Usaha Hotel Syariah A. Kriteria Hotel Syariah Hilal 1, Pub. L. No. 2, Kementrian Pariwisata Dan Ekonomi Kreatif Republik Indonesia (2014).

Http://Www.Kemenpar.Go.Id/Userfiles/L ampiran Tentang Pedoman Hotel Syariah.Pdf.

Lunyka Adelia Pertiwi. "Analisa Perspektif Islam Dan Kosmopolitanisme Terhadap Upaya Global Penanganan Pengungsi Suriah." JISIERA: THE JOURNAL OF ISLAMIC STUDIES AND INTERNATIONAL RELATIONS 1, no. Agustus (2016): 1-13. http://jisiera.insiera.org/index.php/jisiera/a rticle/view/012016/2.

Majelis Ulama Indonesia. "Pameran Halal INDHEX 2018 Siap Digelar.” Majelis Ulama Indonesia, 2018. http://www.halalmui.org/mui14/index.php /main/detil_page/138/24731.

Mangunhardjana, A. Isme-Isme Dalam Etika Dari A Sampai Z. Yogyakarta: Kanisius, 1997.

Mariyanti, Eka, Puti Embun Sari, and Siska Lusia Putri. "Persepsi Konsumen Terhadap Minat Berkunjung Pada Hotel Syariah Di Kota Padang." Menara Ekonomi IV, no. 1 (2018): 917.

Michael Lipka, and Conrad Hackett. "Why Muslims Are the World's Fastest-Growing Religious Group.” Pew Research Center, 2017. http://www.pewresearch.org/facttank/2017/04/06/why-Muslims-are-theworlds-fastest-growing-religious-group/.

Mohamed, Haji Mahmud bin Haji. "Promoting Islamic Tourism in Brunei: Through Customers Understanding Towards the Syariah Compliant Hotel Concepts." University of Nottingham, 2014.

Muhammad Irzal Adiakurnia. "Kejar Wisata Halal Terbaik Dunia, Kemenpar Terapkan Index Wisata Muslim - Kompas.Com." Kompas,
2018.

https: / / travel.kompas.com/read/2018/06/0

6/103647727/kejar-wisata-halal-terbaikdunia-kemenpar-terapkan-index-wisataMuslim.

Muthoifin. "Fenomena Maraknya Hotel Syariah: Studi Efektifitas, Existensi, Dan Kesyariahan Hotel Syariah Di Surakarta.” Surakarta, 2015. https://publikasiilmiah.ums.ac.id/bitstream/ handle/11617/5146/9.Muthoifin.pdf;sequen ce $=1$.

Nasrullah, Muhammad. "Islamic Branding, Religiusitas Dan Keputusan Konsumen Terhadap Produk." Jurnal Hukum Islam 13, no. 2 (2015): 79-87.

Peraturan Menteri Pariwisata dan Ekonomi Kreatif Republik Indonesia Nomor 2 Tahun 2014 Tentang Pedoman Penyelenggaraan Usaha Hotel Syariah, Pub. L. No. 2, Menteri Pariwisata dan Ekonomi Kreatif Indonesia (2014).

https://peraturan.bkpm.go.id/jdih/userfiles /batang/Permen_Parweka_2_2014.pdf.

Puri Yuanita. "Turis Dari 5 Negara Ini Paling Banyak Kunjungi Indonesia | Travel.Dream.Co.Id.” Travel Dream, 2018. https://travel.dream.co.id/destination/turisdari-5-negara-ini-paling-banyak-kunjungiindonesia-180209r.html.

Rahardi, N., and R. Wiliasih. "Analisis FaktorFaktor Yang Mempengaruhi Preferensi Konsumen Terhadap Hotel Syariah." Jurnal Syarikah 2, no. 1 (2016): 180-92.

Rosenberg, Paul, and Hala Matar Choufany. "Spiritual Lodging-the Sharia-Compliant Hotel Concept." Dubai, 2009. https://www.hvs.com/content/2856.pdf.

Saleh, Sri Sundari. "Willingness To Pay (WTP) Dan Faktor-Faktor Yang Memengaruhi Konsumen Dalam Memilih Hotel Syariah Di Kota Bandung." Institut Pertanian Bogor, 2017.

Salma, Fitria Solahika, and Ririn Tri Ratnasari. "Pengaruh Kualitas Jasa Perspektif Islam Terhadap Kepuasan Dan Loyatitas Pelanggan Hotel Grand Kalimas Di Surabaya." JESTT2, no. 4 (2015): 322-39.

Syamsudini, HM. "Cinta Dan Toleransi Perspektif Fethullah Gulen." Edu Islamika 5, no. 2 (September 2, 2013): 378-97. http://ejournal.iainjember.ac.id/index.php/eduIslamika/article/ view/42/35.

Ulfa, Maria. "Analisis Penerapan Prinsip Syariah Di Hotel Arini Syariah Surakarta." Surabaya, 2012. 
Widagyo, Kurniawan Gilang. "Analisis Pasar Pariwisata Halal Indonesia." The Journal of Taubidinomics 1, no. 1 (2015): 73-80.

Wijiatmoko, Andri. "Analisis Pengaruh Harga, Kualitas Pelayanan, Dan Lokasi Terhadap Keputusan Pembelian Hotel Syariah (Studi Pada Pelanggan Hotel Syariah Di Surakarta)." Surakarta, 2016.

Yanita Petriella. "Wisata Halal Beri Kontribusi 30\% Terhadap Target 20 Juta Kunjungan Wisman.” Bisnis Indonesia, 2018. http://industri.bisnis.com/read/20180830/1 2/833354/wisata-halal-beri-kontribusi-30terhadap-target-20-juta-kunjungan-wisman. 